\title{
Imagens do corpo e embodiment das imagens. A circulação da imagem corporal em uma perspectiva histórica (artística) e antropológica (estética)
}

\author{
Marcio Pizarro Noronha*
}

\begin{abstract}
R esumo: O conpo acompanha a produção artística iconográfica e apresenta imagens figuras - do ser humano. Essas figuras podem ser tratadas em seu campo representacional. Na atualidade, a experimentação em arte apresenta não somente imagens do conpo mas ainda o embodiment de suas práticas (com cinurgias, implantes, transplantes). O que é esta mudança paradigmática na imagem corporal? O artigo desenvolve os conceitos de imagens "enconporadas" (embodiment), imagens pictóricas e imagens eletrônicas no contexto artístico da "performance-arte ao retomo à pintura".
\end{abstract}

Palavr as-chave: conpo; embodiment; imagem; história, antropologia da arte.

I

0 corpo da arte contemporânea tem se mostrado o locus mais adequado para a mostra iconográfica das tradições de imagens - e das tensões provocadas em relação a estas - no que diz respeito ao domínio particular da disciplina da história da arte, no âmbito da cultura ocidental.

Em uma disputa intensiva entre diferentes tradições, a arte tornou-se um lugar adequado para a apresentação desses regimes visuais e de suas estratégias de fazer passar novos vocabulários sociais por meio de suportes ou de conteúdos eminentemente tradicionais, bem como 0 de tomar os alvos desse debate para reforçar um campo de tecnologias clássicas.

B ons exemplos desta situação contemporânea encontram-se nos paradigmas enunciados das artes da performance e do retorno à pintura.

D ois temas (e seus conteúdos), duas formas do fazer (e suas tecnologias) e duas resultantes plásticas e visuais vetorialmente díspares em arte

\footnotetext{
* Doutor em A ntropologia pela USP e em História (PUCRS).
}

podem ser vistas, em uma lente histórica e sociocultural, como meios de fazer passar um novo vocabulário social e uma velha tradição plástica por meio do suporte e do conteúdo do corpo (humano).

Performance Art é um tipo de tradição das poéticas plásticas e visuais cuja centralidade de objeto se encontra enunciada na corporeidade do próprio artista. 0 artista toma o seu corpo como objeto central de sua reflexão, fazendo-a integrar-se ao conjunto do que se chama a body art.

These evocative descriptions of the body open up the problematic of body art and lead me to clarify why I use the term 'body art' rather than the perhaps more obvious 'performance art' rubric. I use 'body art' rather than 'performance art' for a number of interrelated reasons. F irst, linking back to the descriptions of the body I have mentioned (all exemplary of a poststructuralist theory of embodied subjectivity), I want to highlight the position of the body - as locus of a 'disintegrated' or dispersed 'self', as elusive marker of the subject's place in the social, as 'hinge' between 
nature and culture - in the practices I adress here. The term 'body art' thus emphasizes the implication of the body (or what I call the 'body/self', with all of its apparent racial, sexual, gender, class, and other apparent or unconscious identifications) in the work. It also highlights both the artistic and the philosophical aspects of this Project - aspects that, I am arguing, are deeply intertwined and mutually implicated in the profound shift in the conception of subjectivity that I am 'performing' here (through body art) as constitutive of the condition of postmodernism. (J ones, 1998, p. 12-13)

A melia Jones, pesquisadora da arte - da performance, da body art -, explica suas relações e a migração do conceito de arte performática para o de body art. Essa concepção permite uma apreensão explícita do que seja um "sujeito na/da corporeidade" (embodied subject) e o modo como a subjetividade se afirma a partir da exterioridade das máscaras e dos papéis ocupados por um eu (self). Essas relações implicam comprender que 0 eu e as máscaras não estão apenas adequados por mera ocupação e que, muito antes pelo contrário, as relações entre eu e corpo sempre passarão pelas marcas da cultura propriamente dita - marcas da aparência e do visível, bem como as marcas traçadas em identificações de caráter inconsciente.

$\mathrm{Na}$ teoria e na história da arte, as práticas performáticas surgem em um determinado momento histórico, no qual o corpo ganha uma notoriedade entre os trabal hos dos artistas de vanguarda e do experimental ismo de vanguarda. A performance implica, de modo geral, uma certa "teatral idade" do artista visual que a di rige ao público - como nos experimentos dadaístas do início do século $X X$.

Assim, artes da performance, que têm oscilado seus objetivos entre os anos 60 e os dias atuais, entre práticas do happening, da arte efêmera, da arte povera, da arte abjeta, de práticas teóricas afinadas aos movimentos da arte conceitual, teriam chegado aos dias atuais em um enlace com o campo das pesquisas sociológico-antropológicas de caráter acadêmico e, mais especialmente, nos programas de pesquisa de caráter experimental, envolvendo rela- ções entre teoria e prática, de formato multicultural ou multidisciplinar, dentre outros.

Elas enunciaram conjunções feministas/ pós-feministas, marxistas/pós-marxistas, do subjetivismo radical, de paradigmas experimentais, de pós-modernismo crítico, todas elas tendo o corpo como meio, suporte plástico e conteúdo da arte.

Nesses termos, artes da performance estar-se-iam vinculando ao movimento mais amplo do embodiment da cultura e de novas chaves interpretativas para o pensamento entronizado em matrizes corpóreas (a filosofia cognitiva e a sua respectiva antropologia são altamente representativas desse movimento de matrizes inglesas). ${ }^{1}$

Por outro lado, o movimento de retorno à pintura, anunciado no final da década de 1990, tem suas raízes paradigmáticas na prática de pintores contemporâneos, cujo expoente paradigmático é Francis B acon. ${ }^{2} \mathrm{~N}$ esse paradigma, 0 corpo é alvo de uma estratégia para ressaltar ainda e sempre as qualidades específicas da pintura a óleo e de uma definição eminentemente tecnológica do fazer - especializado - artístico.

1. Essa discussão tem sido 0 alvo de diversos outros artigos e do trabalho de orientação de dissertação de mestrado Body-Steria, de Andréa Pita, no Programa de Pós-Graduação $M$ estrado em Cultura Visual. N essa perspectiva, identificamos as leituras da performance com o campo da pesquisa denominado de performance studies. Neste, os resultados objetivos são traçados em torno de experimentos de registro audiovisual, pesquisa de campo, processos rituais e concepções socioantropológicas e artísticas do que seja a performance. Essa reflexão somou-se ao entendimento das relações, na movimentação acadêmica norte-americana em torno do "pós-modernismo" (final dos anos 1970 e década de 1980), com a formação de departamentos e programas de pesquisa. $\mathrm{Na}$ atualidade, os desdobramentos desses estudos levaram ao desenvolvimento do conceito de performative writing, uma conjugação de escrita subjetiva, marcada culturalmente por posições étnicas e de gênero, dentre outras.

2. Em artigo recente, "Corpos pintados, corpos pictóricos: imagens do corpo na história cultural", apresentado no Congresso da Anpuh (XXIII Simpósio Nacional de História, Londrina, Paraná, 2005), apresento a proposição do paradigma baconiano para a pintura contemporânea e sua estratégia formal de fazer passar, nos moldes de uma imaginação do tempo presente, o foco central de sua interpretação conservadora do conteúdo da arte da pintura. Nesses termos, a pintura seria uma tecnologia cristalizada no campo das realizações do óleo (pintura a óleo). Os conteúdos visuais, as imagens resultantes, seriam os disfarces do pintor, que elege o corpo como objeto hierarquicamente superior no material das artes ocidentais e que pode fazer passar a credibilidade de sua tese técnica. 
Essa ação da pintura diz respeito à tradição iconográfica ocidental que hierarquizou seus conjuntos de imagens e deu ao corpo - humano - um lugar privilegiado na história da arte (N oronha, 2005).

Desse modo, o corpo - matérico, humano - veio a se tornar um suporte para o desenvolvimento da obra de arte e, como tal, um suporte de signos que estão contidos em nossa própria tradição artístico-cultural.

Sendo esse corpo um suporte, acaba constituindo conjuntos imagéticos que servem para figurar as questões da corporei dade e do próprio humano nos tempos atuais.

Por costume, tratamos dessas figuras como representações visuais, em um campo mental, de uma determinada real idade que foi abstraída no processo de produção da obra e que serve como metalinguagem da realidade. $\mathrm{Na}$ atual $\mathrm{i}$ dade, a corporeidade ganha outro dimensionamento. Para aquém da representação, vivemos um procedimento de embodiment da própria cultura que, ao invés, de simplesmente tomar 0 corpo como suporte para a metáfora, faz da cultura uma metáfora do corpo. Assim, esse conjunto iconográfico - produto da arte contemporânea - não é apenas legível, mas transformase ele próprio em visível, val orizando as práticas corporais e sua exploração intensiva e extensiva por parte dos artistas com suas resultantes, criando um conjunto de experimentações do corpo que se transformam em obras de arte tais como as cirurgias, os transplantes e os implantes, operações da cultura biomédica que são obsessivamente perseguidas pelo domínio artístico, transformando o domínio biológico em uma espécie de paradigma do estético, ou, quem sabe, fazendo reger a estética pelo biomédico.

$\mathrm{N}$ a resultante visual e audiovisual desses proj etos artísticos, temos uma espécie de coleta dessas experimentações, caracterizando algo como o registro etnográfico da realidade e a proximidade do artista, em um duplo papel, como informante privilegiado e observador privilegiado da própria realidade contemporânea e da corporificação do conjunto visual ${ }^{3}$ (Foster, 2002).

E sse paradigma de imagens corporificadas seria uma espécie de duplo ou de complemento binário das imagens descorporificadas - da substituição el etrônica do visível pelo legível, como sinal e como código. Oferece-se ao espectador e ao leitor do visual uma dupla e oponente entrada para 0 mundo das imagens. Por um lado, o embodiment e, por outro, o sinal e o código. Com isto, podemos entender as afirmações e diagnósticos da cultura das imagens na contemporaneidade, que veriam a anunciação do fim da imagem visual e, mais especial mente, da imagem plástica. $\mathrm{N}$ a contemporaneidade, 0 embate e o direito em torno do campo da visualidade centrar-se-iam em uma luta entre imagens voltadas para a sensibilidade háptica - todas aqueles que exigiriam uma participação mais integral da corporeidade em detrimento da dominância hierárquica da sensibilidade óptica (e a crise da função escópica, do imaginário) - e para uma sensibilidade de leitura de códigos, de imagens-impulso, de escritura eletrônica, em que a imagem é, ela própria, o seu código, colando imagem e imaginação na rede abstrata dos símbolos. ${ }^{4}$

Em se tratando de um levantamento e de uma reflexão em torno da corporeidade, mais de caráter de etnografia visual e de estudo ainda iconográfico, reconhecemos, portanto, a presença de três grupos de imagens: imagens visuais, com matrizes bidimensionais e que teriam se

3. $\mathrm{O}$ trabalho de $\mathrm{Hal}$ Foster trata especificamente dessa problemática das relações entre arte e etnografia no final do século XX. FOSTER, Hal. The return of the real: the avant-garde at the end of the century. Cambridge, M assachusetts / London, England: The M IT Press, An October B ook, 2002.

4. Essa questão, de ordem teórica, põe na ordem do enfrentamento as teorias do imaginário psicanalítico (de matriz lacaniana) e do imaginário bachelardiano e seus desdobramentos e ampliações na tese do imaginário sociocultural de Gilbert Durand. Em última instância, o problema de fundo estaria em dar um novo estatuto para o conceito de imagem e reconhecer o impasse existente na abordagem de uma "civilização das imagens", já que estas teriam de ser entendidas de outro modo, abandonando as relações mais imediatas entre imagem e senso comum que as colocam no domínio da visualidade bidimensional. É o tema do imaginário lacaniano associado à questão do "que é a superfíciequadro" e do que é a "superfície-espelho", ambas remetendo para as condições de uma imaginarização de caráter fundamentalmente visual. Se há uma crise dessa produção imaginária visual - e plástica -, quais seriam os direcionamentos que a substituiriam? 0 mal-estar das imagens poderia ser enunciado também como sendo o mal-estar da cultura ocidental com sua própria tradição pictórica, dos anos 70 do século XX para cá. Esse tema encontra-se parcialmente desenvolvido em artigo apresentado no seminário de pesquisa da Faculdade de A rtes Visuais (UFG) no ano de 2004, cujo tema era a teoria lacaniana da pintura. 
sustentado construtivamente no paradigma pictórico e nas relações entre os planos técnico e estético; imagens que resultam em produtos visuais, mas que se caracterizam por estarem centradas em um campo produtivo de caráter sensorial háptico (as artes da performance, os registros audiovisuais em vídeo), e as imagens que resultam em produtos visuais nascidos no interior de "artes da escritura digital", exigindo um domínio do código, um entendimento do funcionamento de determinados programas e, por vezes, uma sensibilidade háptica reduzida (recursos do tato, uso do mouse etc.).

$N$ esse sentido, reduzindo nosso experimento a um desses registros técnico-estéticos, a etnografia visual privilegiará a abordagem do que denominamos aqui de imagens corporificadas.

A corporificação da cultura e da imagem seria, em nossa hipótese lógica, um retorno à oposição entre imagens corporificadas e imagens descorporificadas e faria passar algo das imagens pictóricas e da tradição visual ocidental.

Isto significa dizer que entende-se justamente a presença do corpo como sendo a marca de mecanismos internos à lógica da produção artística de fazer sobreviver (e de fazer passar, ainda) el ementos de uma iconografia da tradição imagética ocidental - da cultura e da arte do mundo ocidental - dentro da perspectiva histórica de que o Ocidente é uma invenção ideológica do cristianismo e, portanto, um fato cultural construído historicamente no interior da cultura medieval.

Em suma, o que isto pode estar nos contando? Que, em realidade, artes da performance e artes pictóricas seriam, ambas, estratégias de retradicionalização, de reafirmação de modus operandis artísticos que estariam deixando de ser hegemônicos nas concepções evolutivas e tecnológicas da arte. Então, as três categorias elencadas poderiam ser novamente pensadas como duas e operações do pensamento binário seriam reafirmadas.

II

Tomada ciência da situação em torno das imagens produzidas no registro da corporeidade, imagens construídas com o próprio corpo ou com corpos al heios, instalações de corpos, devemos agora, na prática em torno dos constructos dessas mesmas imagens, localizar e identificar a multiplicidade de suas categorizações/classificações.

A ssim, na classificação adaptada de Francesca A Ifano M iglietti (M iglietti, 2003), o conjunto dessa corporificação das imagens leva-nos a identificar um certo registro particularmente especializado do corpo e da imagem corporal no campo da arte, propriamente dito:

1. A simagens de uma marcação, todas elas envolvendo em maior ou menor grau uma caracterização de situação ritual ou de performance tomada como rito:

- são os experimentos (em body-art e em performance) e as iconografias que envolvem processos de produção de dor no corpo real, geralmente do artista;

- são os experimentos e as iconografias que vinculam a produção artística a um determinado tipo de realidade e experiência religiosa, tomando a arte na sua afinidade ou identidade com a religião e caracterizando-se por uma grande proximidade com as culturas e tradições religiosas particularizadas na história de vida do artista;

- são os experimentos e as iconografias que vinculam a arte ao sexo e ao exercício da sexualidade;

- são os experimentos e as iconografias que vinculam a arte à morte e à produção simbólica ou no real do corpo da morte individual.

2. A s imagens do impacto, do choque, ou o corpo do impacto, subdividindo-se em diversas experiências e iconografias:

- 0 impacto do estranhamento, as imagens do estranho, do estrangeiro, do Outro, distribuindo em iconografias e experiências do estrangeiro, desdobradas por sua vez nas situações do conflito étnico, do conflito religioso, dos hábitos particularizados de uma determinada cultura e no caráter testemunhal-depoimental da obra de arte, do (auto-)exílio, das fugas, dos processos migratórios, dos movimentos populacionais, 
dos movimentos das massas, dos trânsitos, das fronteiras;

- o impacto ou o choque da transgressividade e da ul trapassagem dos limites da humanidade cultural mente situada, através do corpo da loucura, do corpo animal, do corpo vegetal, do corpo mineral, levandonos a uma reflexão da cosmologia implicitamente presente em nossa cultura, por meio do valor dado à arte;

- o impacto ou o choque da transgressão de fatos condicionados como sendo moralmente valorados tais como a violência, o crime, o pecado, o que nos leva aqui a uma etnografia que a arte tem produzido em relação aos modos como nossas sociedades enfrentam os problemas do valor, sugerindo artes e corporeidades distintas, advindas das experiências sociais da marginalidade, do estigma social, das diferenças de gênero e da expressão sexual, incluindo aí os limites culturalmente impostos ao domínio do biológico (que jáé quase uma categoria de trânsito para uma outra instância do corpo).

3. As imagens enigmáticas ou os corpos enigmáticos:

- a fusão ou a ultrapassagem da corporeidade humana com o universo propiciado pelo mundo tecnológico, criando o estatuto do híbrido tecno-humano, recaindo aqui nos estudos das próteses e das órteses corporais em um sentido mais abrangente;

- a fusão ou a ultrapassagem da corporeidade real (biológica, sustentada na existência material do corpo) para uma corporeidade ficcional, não mais como representação (pois esta sempre esteve presente no campo da imagem visual, bem como no texto literário), mas associada ao fenômeno de uma estética social do hiper-real, gerando fenômenos diversos como a arte hiperreal ista, 0 interesse exacerbado pela fotografia, a estética pornográfica que envolve o sexo e a violência social.

Estes três conjuntos e suas respectivas subdivisões podem ser pensados ainda de um outro modo. Nesta classificação, tentaremos aplicar categorizações técnicas, socioculturais e históricas a esses conjuntos descritivos acima enunciados. Para começar, tratemos rapidamente das questões que dizem respeito ao âmbito técnico (das técnicas artísticas). N esse registro, temos de pensar os diferentes tratamentos dados ao corpo na arte contemporânea, ou tipos de uso e os meios que servem como suporte ou registro documental.

Podemos identificar aqui que o corpo tomado pela arte contemporânea, não apenas no seu caráter representacional ou como demonstração figurativa e/ou simbólica dos tratamentos e das estéticas da corporeidade humana em cada período histórico, é um corpo dado para a fragmentação, para a distorção, para a expressão, para a gestualidade (happenings, performances), para a documentação (hiperrealismo, fotografia etnográfico-artística, pornografia). A lém desses "signos rotatórios" parafraseando a expressão de Octavio Paz -, temos de identificar ainda a multiplicidade e a complexidade dos modos como se dão a apreensão (sensorial e perceptiva) e o entendimento (cognição) do corpo, como materialidade e como signo.

Tecnicamente, os meios utilizados para produzir essa iconografia e/ou as experiências - sejam elas do artista ou do público - são os mais diversos, indo desde os suportes tradicionais da pintura, da escultura, do desenho, da gravura e de outros meios de reprodução técnica, passando pela fotografia e mais contemporaneamente pela arte postal (mail-art) e diversificando-se nas direções do happening/ performance/body-art (especialmente dos anos 60 do século XX para cá) e dos meios tecnológicos, incluindo aí o uso do vídeo (videoarte), a instal ação, a videoinstalação e as formas mais contemporâneas das relações entre arte e tecnologia, seja pela aplicação de meios ao corpo (próteses e órteses), seja pela web-art e pela net-art.

Em relação a esse registro, não podemos chegar a um determinado consenso, pois não existe um meio predominante nem um suporte mais adequado. 0 que temos é a absorção de novos meios de registro, de suporte, de experimentação. 
Esses meios passam a complexificar a problemática da apreensão e do entendimento, mesmo quando caminham na direção da descorporificação; implicam aí uma transformação do corpo em "puro aparato sensório-perceptivo e cognitivo", por meio do privilegiamento dealguns de seus órgãos sensoriais.

No que tange aos conjuntos de categorias mais amplamente sociológicas, podemos registrar um conjunto reincidente de temas e conteúdos nessas "obras corporais":

- corpo, sexo e gênero: os modos de apreensão artística das realidades e das formas adotadas pelo corpo em suas afirmações da masculinidade e da feminilidade, de acordo com as culturas, envolvendo ainda as transposições desses modelos para as formas trans- (transgender, queer culture), com obras que tratam de histórias de vida, experiências do sexo, definições de gênero nas obras (arte homossexual, por exemplo), noções de valor e de pecado, erotismo e pornografia;

- corpo e psicossomática: a psicossomática pode levar a um modelo teórico predominantemente organicista ou a um modelo teórico transcendentalista acerca da obra de arte, com estados intermediários entre um e outro, manifestando-se nos modos da apreensão e da cognição artística dos fenômenos que atingem ou que são produzidos no e pelo corpo, com obras que tratam e envolvem a sinestesia, a dor, a religiosidade, o sofrimento físico, emocional e espiritual, a purificação, os ritos de passagem, o sexo como ato e o sexo como rito e purificação, a loucura, o corpo-O utro (da animalidade, do vegetal, do mineral) e suas relações com o universo cosmológico (pensamento simbólico), reconcepções da natureza e do ambiente, reconcepções da corporeidade, a criação de objetos impermanentes com o próprio corpo ou com os seus resíduos (arte abjeta), a produção de marcas corporais (tatuagens, cicatrizes e outras) e, finalmente, os estados da morte como registro estético de eventos da morte (nas iconografias) ou como promoção da própria morte como evento estético (M ishima, Rudolf Schwartzkogler);
- corpo e estados violentos: as questões do impacto podem ser traduzidas em um amplo campo de estudos da violência física (real) - os crimes, os homicídios, os acidentes de trânsito, por exemplo - e simbólica - 0 pecado, o estigma, para citar al guns casos - e nos modos de apreensão artística dos estados de autoviolação/automutilação até os registros da violência física e da violência simbólica sofridas na condição da corporeidade; nesse âmbito, podemos pensar nas mesmas séries de artistas que, envolvendo as duas categorias anteriores, podem promover a mutilação em torno da sexualidade, a violência como estado psicossomático que visa à ascese do corpo (ascetismo pela via da violência, na tradição do cristianismo), a violência como estética do banal, partil hando os mesmos códigos visuais da cultura pop e dos fenômenos de massa, em um paradigma (a)enunciado por A ndy Warhol, com suas séries de procurados pela polícia, mortes em acidentes, cadeiras elétricas;

- corpo e marcas culturais: etnicidade, religiosidade, conflitos, hábitos, (auto-) exílio, fugas, processos migratórios, movimentos populacionais planetários, movimentos de massa, fronteiras, trânsitos, estigmas sociais, marginalização, diferenças, loucura, livre expressão sexual, questões de gênero e transgênero, fazendo das obras uma espécie de registro documental específico e especializado;

- corpo, erotismo e pornografia: uma temática específica em torno do corpo, que envolve categorias anteriores, especialmente sexo/gênero e violência, pois sua produção se dá no interior de um conjunto imagético já marcado pelo universo do gênero (da cultura), identificadas culturalmente com estados da promoção do sexo e da sexualidade e das formas específicas do seu uso social, muitas vezes resultando em obras que criam personagens;

- corpo, cotidianidade e intimidade: os modos de apreensão artística do corpo identificados culturalmente a um estado ou a um regime emocionalmente qualificado como sendo o da intimidade (esfera da vida 
íntima) e valorando ainda os registros da vida cotidiana, do tempo presente em sua precariedade e fugacidade, em um estado estético que se sustenta na ideologia da modernidade e do estilo de vida burguês e, muitas vezes, realizando verdadeiras etnografias visuais. A qui, as questões não são tanto de caráter cosmológico quanto se oferecem como imagens testemunhais (e testamentos) da noção de estilos de vida;

- corpo, o real e o virtual: aqui estamos diante da grande maioria dos estudos recentes em torno do corpo e digo em torno por se tratar de reflexões que estão preocupadas em ver e em pensar estados tecnológicos envolventes, a hiper-realidade, a ficcionalidade do real, o estatuto do real e do virtual, a arte hiper-realista, a arte tecnológica (net, web), chegando a cruzar com alguns dos estados aparentes dessas situações, tais como a violência, a pornografia, o transgênero, e com as pesquisas acerca dos modos de apreensão sensorial-perceptiva e de cognição dessas novas realidades e experimentos. Como disse, este éo domínio predominante na atual idade, em grande parte devido ao próprio impacto das novas tecnologias sobre as relações sociais e uma redefinição da própria cultura, com a construção de uma espécie de tecnocultura.

Como vimos, cada um desses registros do corpo e da corporeidade privilegiará seus meios, técnicas e suportes, adequados ao seu modo de entendimento do fazer artístico e de suas linguagens.

Passemos agora para o segundo ponto de nosso trabal ho. A pós este levantamento e esta organização da temática, no âmbito deste artigo, trataremos de elencar apenas um desses itens, com os seus respectivos cruzamentos, realizando uma etnografia visual. 0 que queremos ressal tar com isto é a importância da função imagética na pesquisa e o modo como esta se sobrepõe ao texto escrito, levando em conta o sistema simbólico que é a imagem em suas funções.
III

\author{
"A pintura pensa. Como? \\ É uma questão infernal. \\ Talvez inaproximável para \\ o pensamento." \\ (Didi-Hubeman)
}

Passemos agora a algumas questões metodológicas. Resumindo a problemática instaurada pel os métodos clássicos e sua adoção por grande parte da história e da antropologia da arte e, decorrentemente, por parte das outras disciplinas humanísticas e sociais, o tratamento dado às imagens baseou-se fundamental mente em métodos formal istas e em métodos iconográficos/iconológicos. No primeiro caso, os estilos acabam por se desenvolver como maneiras pelas quais uma cultura-sociedade encontra os mei os de exprimir seu gosto, ou seja, a arteé um veículo expressivo da cultura. No segundo caso, a iconol ogia acaba por se tornar um grande sistema de representações visuais (na sua perspectiva histórica) ou um conjunto arquetípico (na sua perspectiva ahistórica).

U ma perspectiva que pudesse ser chamada de antropologia visual ou de história visual deveria dirigir-se prioritariamente ao tratamento das potencialidades da visualidade como, ela própria, meio de expressão, de descrição e de invenção da realidade. Para um autor como Gombrich, tradicionalmente utilizado pela história da arte e reapropriado pela antropologia visual, uma possível menor capacidade enunciativa da visualidade não implica hierarquização e uma diferença e uma especificidade do meio e do seu tratamento. 0 que deve ser pensado é a imagem com base em suas funções e como sistema simbólico.

$\mathrm{Na}$ atualidade, a teoria da arte tem refletido muito especial mente sobre esse tema e procura dar suas contribuições de suma importância ao estudo da imagem artística e da imagem como um todo.

Daniel A rasse, teórico da arte e historiador, desenvolve importante reflexão sobre 0 ato de ver e não o de ler uma obra visual:

[...] critica a ocultação iconológica da obra visual sob textos verbais, ao renunciar à análise da diferença que se instaura entre uma pintura, 
por exemplo, e sua fonte literária, e propõe, ao contrário, uma série de critérios de análise que examinem a maneira pela qual a imagem constitui-se com meios e peculiaridades próprios. 0 que, ao invés de "fazer ler" a imagem, faria "vê-la". (Calabrese, 1987, p. 41)

N essa mesma perspectiva de trabal ho é que tem se desenvolvido a teoria da arte francesa, tomando a imagem artística como sendo a "economia paradoxal do sentido simbólico, semiológico e discursivo" (L ouis M arin). A pós o desenvolvimento proposto pela sociologia de Pierre Francastel e pela antropologia de Claude LéviStrauss (e a teoria artística estruturalista de J ean-L ouis Schefer), o pensamento de Louis M arin, no dizer de Huchet, foi o primeiro a sistematizar uma perspectiva de tratamento da imagem como imagem falante. M antendo a matriz na iconografia - afinal, a iconografia é a prática de campo (a etnografia) da história da arte, equivalendo as relações entre história e teoria às relações entre etnografia e etnologia - , M arin é o primeiro a chamar a atenção, no pensamento francês, para as limitações da transferência da imagem ao significado, demonstrando a complexidade de uma teoria da representação visual e do visível, que identifiquem o poder da imagem e sua tarefa antropológica de fazer funcionar 0 corpo simbolicamente, em um jogo de presenças e ausências.

Posteriormente, dentre esse grupo de teóricos franceses, temos Hubert Damisch e seu "discípulo" Didi-Huberman. Damisch desenvolve uma teoria com base na imagem, ou seja, el e enuncia que a imagem artística sustenta em si um determinado lugar de representação. A o estudar as repetidas e variadas imagens das nuvens na história da pintura, em seu desdobramento espacial e temporal, o autor enuncia uma teoria que surge do modo como o objeto foi tratado e o que ele se tornou visualmente para nós. E le parte do objeto visível e retorna a ele. 0 objeto nuvem carrega em si um acúmulo de informações e de idéias sobre as idéias - ou seja, representações de representações. Esse objeto não apenas explicita aqueles conteúdos tratados pela tradição iconológica, mas ampliase para mostrar o desdobramento da natureza matérica da própria pintura. 0 problema dos objetos a serem pintados e do desenvolvimento de uma tecnologia peculiar a cada objeto que entra na cena da representação do visível torna a produção do objeto concreto, ela própria, um raciocínio de ordem teórica e portador de uma teoria (Calabrese, 1987).

0 exemplo da nuvem é esclarecedor. Desde a I dade $M$ édia até 0 século $X I X$, a nuvem é um objeto recorrente, mas com funções variáveis, um instrumento que é um pouco menos que um motivo e pouco mais que um grafo. E m sua origem serve (quase como nas simulações cênicas do teatro) para introduzir o sagrado no profano (isto é, para manifestar as aparições, a ascensão de Cristo, as visões místicas e assim por diante): serve, em suma, para justificar a inserção de um plano metafísico num plano físico, sem colocar em dúvida a estruturação deste último. No Renascimento, seu papel é bem mais ambíguo, porque a regulação do quadro é assegurada pela perspectiva. A nuvem serve mais para indicar inferencialmente 0 irrepresentável, ou seja, o infinito; o infinito é mascarado pela nuvem, mas ao mesmo tempo, é designado por ela (paradoxalmente isso garante o equilíbrio teórico do quadro, porque assegura o val or da teoria científica que modela 0 dispositivo espacial do quadro). E assim por diante: cada inovação no enredo teórico do saber produz um deslocamento funcional do motivo / grafo 'nuvem' ea reelaboração de uma nova teoria da representação. (Calabrese, 1987, p. 212-213)

Isto quer dizer, de modo mais simples, que a imagem não funciona ilustrativamente, mas é el a própria uma representação complexa, diversa da representação conceitual (e da linguagem, no sentido lingüístico, que estamos acostumados a tratar, quando falamos da imagem do sentido barthesiano, por exemplo). Se a imagem não ilustra e tampouco funciona tal e qual um conceito, ela deve obedecer a um outro tipo de lógica. Segundo Damisch, essa lógica é a dos dispositivos visuais (dispositivos da representação visual). No caso por ele estudado, esse dispositivo é enunciado com base em uma "etnografia das imagens", visando encontrar os el ementos visuais que perturbam a organização de um modelo hegemônico da visualidade. Damisch e Didi-Huberman concordam plenamente com a ambigüidade do signo visual e sua capacidade de disseminação de sentidos diversos 
ao sentido apontado como sendo o significante cultural. A s nuvens eram os dispositivos pictóricos - dentro da lógica da imagem pictórica que serviam aos artistas para disseminar um nãosentido, perturbando a interpretação vigente da concepção do espaço renascentista e barroco afirmada pelos formalistas, mas também pelos estudos da iconologia e mesmo pela sociologia de Francastel. Portanto, o material coletado iconograficamente é utilizado inversamente ao modo da iconologia. A o invés de determinar um significado e uma espécie de dicionário de símbolos, a investigação contra-iconológica aponta para o reducionismo literário apresentado nas abordagens da iconologia.

A nuvem passa a ser o sintoma da desordem representacional, pel o processo de disseminação e da produção do não-sentido no campo imagético.

Questão semel hante havia sido enunciada por Severo Sarduy, em sua análise do barroco como sistema artístico e sistema científico, dentro da cultura das idéias. 0 que demonstra Damisch é que pinturas são objetos teóricos tanto quanto as próprias teorias, tal o grau de sua sofisticação, das operações que geram a sua produção.

Transcrevendo, para nosso estudo em antropologia e história da arte, uma história e uma antropologia visual do corpo não podem prescindir de pensar no corpo como um objeto teórico altamente complexo que é reunido a outro obj eto teórico, a imagem do corpo, pois é dela que estamos a tratar e é com ela que estamos a trabalhar. 0 corpo pode e deve ser olhado com um objeto teórico, ele próprio representação visual, lugar social e teoricamente relevante.

Como podemos pesquisar uma antropologia e uma história visual do corpo na arte contemporânea?

Entendendo a questão proposta pelo método iconológico, temos o seguinte: a iconologia é um raciocínio de imagens, uma forma lógica mimética. 0 estudo do significado das obras opera em três níveis de significação:

- Os motivos. Tema primário ou natural, subdividido em factual e expressivo identificação das formas
- A iconografia. Tema secundário ou convencional, identificação dos temas de uma obra e de sua combinação

- A iconologia. Terceiro tema ou o significado intrínseco ou conteúdo da obra de arte, compreendendo o posicionamento básico que, num dado período, nação, classe ou cultura, condiciona 0 artista e é simbolizado na obra.

Ou ainda:

- Estrato primário. Descrição fenomênica e o conhecimento do estilo.

- Estrato secundário. 0 significado, sua transmissão e permanência, pela via literária, com a pesquisa iconográfica e a teoria dos tipos.

- Estrato terciário. Relação entre dados da figuração e representação da experiência (sistema cultural de uma época na atividade representativa).

- Estrato quaternário ou final. Descrição do significado da obra de arte como documento. A iconologia.

Tomando como base a tradição iconográfica no estudo das imagens e a condição da especificidade da visualidade como objeto de pesquisa e como objeto teórico na/da realidade, estamos lidando inicialmente com um objeto visual e suas variações visíveis (incluindo aí não apenas as imagens, como também os meios e os modos, ou seja, os suportes e os métodos de construção das imagens) e de sua significação. A o invés de ser imediatamente vinculado ao conjunto exaustivo de temas, tal como o fizemos na primeira parte deste texto, invertem-se a posição e os objetos e são el es próprios a teorização de al go e não meros reflexos de categorias e representações exteriores. A ssim, ao desenvolver a teoria do corpo identificada na obra, devemos identificar os modos como a obra produz, evoca, sugere, instaura, constrói etc. um corpo efetivo e posto diante de algo ou al guém para gerar seus ef eitos. $\mathrm{O}$ u como diria A rasse, ao invés de saltar da descrição fenomênica e/ ou formal para o patamar da interpretação (tal como ocorre na iconologia e, em certa medida, na hermenêutica e no interpretativismo), dá-se 
um giro na direção do objeto visual, dentro de um determinado sistema do visível. 0 que 0 objeto nos diz acerca do corpo como uma imagem é, portanto, uma teorização dele. A imagem não é uma ilustração, mas uma teoria de si mesma.

A s imagens do corpo como imagens artísticas do corpo são um tipo especial de economia visual do sentido, traduzindo-se em dispositivos visuais que deverão ser nomeados no decorrer de cada imagem em seu registro - assim, um dispositivo visual deve ser identificado primeiramente em seu meio técnico (pictórico, escultórico, gráfico etc.), logo em seguida em seu registro estilístico/sua estética (clássica, barroca, etc.) para que tenha 0 tratamento adequado a esse tipo especial de imagem do corpo.

A imagem artística é um tipo especial de pensamento em sua realidade existencial. 0 teórico vai ainda mais longe em suas aproximações paradigmáticas entre corpo, pensamento e arte, tomando as imagens artísticas como criações/encarnações/corporificações o que ele chama de incarnat. 0 sentido da imagem artística não pode ser substituído por uma esquematização empobrecedora da realidade iconográfica-etnográfica, pois o documento visual é dessemelhante ao documento escrito e vive com este num estado de simbolização mútua - uma espécie de cópula da imagem com o texto, na dessemelhança (na diferença), ou seja, não há espel ho que sustente, mas há relação simbólica. Huchet:

Para terminar, cito uma afirmação de

$N$ a Idade M édia, muitas imagens (crucificações, por exemplo) tinham uma certa função de produção de sintomas, de estimulação de uma participação sintomática do crente no poder 'encarnacional' (inacarnationnel) dessas imagens. Didi-Huberman utiliza esse material histórico de tal maneira que a antropologia do visual [grifo meu] procurada por el e encontrase levada a escolher referências pontuais trazidas num gesto basicamente iconológico: 0 de basear o desvelamento da força das imagens a partir de documentos que lhes são contemporâneos. A busca de sintomas medievais (por exemplo, tal corpo de C risto constituído do derrame de uma mancha que impede a identificação da anatomia de um corpo supli- ciado) visa reatar com concepções da função da imagem de arte longínquas das nossas, cujo anacronismo abre as possibilidades produtivas inerentes à rememoração e ao ressurgimento de um paradigma intempestivo. M as a promoção de uma série de argumentos suscetíveis à generalização em um nível mais universal parece torná-los as al egorias de uma visão crítica que, nisso, perde seu impacto transcendental. (DidiHuberman, 1998, p. 17-18)

Com isto apreendemos a afirmação apontada no título deste trabal ho, fal ando da imagem corporificada e do corpo imaginarizado, em via de mão dupla.

A iconografia (como um tipo especial de etnografia) é ainda um fundamento para a feitura de uma antropologia e de uma história das manifestações artísticas, que não se queiram uma reflexão exclusivamente de caráter filosófico, revelando a corporificação da imagem na arte contemporânea como mais um elemento que nos auxilia a pensar nas condições da produção artística.

$\mathrm{Na}$ resultante visual e audiovisual de diversos projetos artísticos, temos uma coleta dessas experimentações, caracterizando uma espécie de registro etnográfico da realidade e a proximidade do artista, em um duplo papel, como informante privilegiado e observador privilegiado, da própria real idade contemporânea e da corporificação do conjunto visual (Richard Wollheim).

Esse paradigma de imagens corporificadas seria uma espécie de duplo ou de complemento binário das imagens descorporificadas - da substituição eletrônica do visível pelo legível, como sinal e como código.

U ma pesquisa dirigida para esse caminho reconhece que sua coleta de imagens, para uma antropologia que se proponha da arte - não reduzida ao domínio do ensaio de antropologia do visual -, deve querer fazer sentido no domínio iconológico. Esse gesto estético e imagético baseia-se no modo como uma imagem tem força diante de outros conjuntos documentais que Ihe são contemporâneos, sendo significativa em uma cadeia de significações - aqui já fica explicitado que não é de qualquer imagem que se está falando.

Pois nem tudo é arte, ou quase nada é arte contemporaneamente a nós. 
U ma sintomatologia visual da contemporaneidade deve ser instaurada pel as imagens em questão em paralelo a outros funcionamentos da imagem que serão evocados e trazidos à cena, como sendo integrantes de uma espécie de "olhar arcaico ou arcaizante" a respeito da imagem - devido ao esquecimento moderno (olhar moderno, científico, cartesiano).

U m corpo pode ser constituído de matérias não corporais ou descorporificantes-descorporificadas, impedindo ao espectador reencontrar a visão convencionalmente anatômica da realidade física do corpo humano.

D esse modo, essas imagens corporificadas só podem pretender a identificação dos modos como a obra produz, evoca, sugere, instaura, constrói etc. um corpo efetivo - corpo dos af etos - e posto diante de algo ou alguém para gerar seus efeitos.

A bstract: The book accompanies the iconographic artistic production and presents images - figures - of the human being. This figures can be treated in this representational champ. In actually, the experimentation in art presents not simply body images but yet the embodiment of this artistic practices (with surgery, implants, transplants). What is this paradigmatic change in book image? The article developments the concepts of embodiment images, pictoric images and electronic images in the artistic context of "performance art to retum a painting".

K ey-words: body; embodiment; image; art history; art anthropology .

\section{Referências}

ARAUJ O, H.R. DE (Org.). Tecnociência e cultura: ensaios sobre o tempo presente. São Paulo: Estação Liberdade, 1998.

BAUDRILLA RD, J ean. L'echange symbolique et la mort. Paris: Gallimard, 1976.

BATESON, G regory. La cérémonie du Naven. Paris: Les Éditions de M inuit, 1986.

BECK ER, Howard. M étodos de pesquisa em ciências sociais. 4. ed. São Paulo: Hucitec, 1999.

CA LA BRESE, Omar. A idade neobarroca. Lisboa/ Sao Paulo: Ed 70/M artins F ontes, 1988.

CIRLOT, Juan-Eduardo. Diccionario de simbolos. M adrid: Siruela, 1997.
DERY, M ark. Velocidad de escape. La cibercultura en el final del siglo. M adrid: Siruela, 1998.

DOM INGUES, J. M. Teorias sociológicas no século XX. Rio de aneiro: Civilização B rasileira, 2001.

FEHER, M ichel. NA DDA FF, y TAZI. F ragmentos para una historia del cuerpo humano. 3 v. M adrid: Taurus, 1990.

FOSTER, $\mathrm{H}$ al. The return of the real: the avant-garde at the end of the century. Fifth printing. Cambridge, $M$ assachusets/L ondon, England: The MIT Press, A n October B ook, 2002.

FOU CAULT, Michel. A ordem do discurso. São Paulo: L oyola, 1996.

GEERTZ, Clifford. A interpretação das culturas. Rio deJ aneiro: Zahar, 1978.

HA RAWAY, Donna. Simians, cyborgs, and women: the reinvention of nature. NY: R outledge, 1991.

LEVI-STRA USS, Claude. Antropologia estrutural. Rio deJ aneiro: Tempo B rasileiro, 1976. . Mito e significado. Lisboa: Ed. 70, 1981. . M irar, escuchar, leer. M adrid: Siruela, 1995.

M IGLIETTI, Francesca A Ifano. Extreme bodies: the use and abuse of the body in art. Milano: Skira Editorial, 2003.

NORONHA, M arcio Pizarro. Corpos pintados, corpos pictóricos: imagens do corpo na História $\mathrm{Cultu-}$ ral. Congresso da A npuh - XXIII Simpósio Nacional de História, Londrina, Paraná, 2005. Publicação em CD-ROM.

PANOFSKY, Erwin. Estudios sobre iconologia. M adrid: A lianza E ditorial, 1982.

RIBEIRO, Branca Telles; GA RCEZ, Pedro M. (Org.). Sociolingüística interacional. Porto A legre: AGE Ed., 1998.

SHUSTERM A N, Richard. Vivendo a arte: o pensamento pragmatista e a estética popular. São Paulo: Editora 34, 1998.

TURNER, Victor. La selva de los simbolos. M adrid: SigloXXI, 1997.

VAN DIJK, Teun. Cognição, discurso e interação. São Paulo: Contexto, 1992.

VILLA ÇA, Nizia; GOES, Fred. Em nome do corpo. Rio de Janeiro: Rocco, 1998.

Em pauta: corpo, globalização e novas tecnologias. Rio de J aneiro: M auad / CN Pq, 1999. 